\title{
Jumping Over the Fence: The Stories of Senior High School Students
}

\author{
Herdin Gray Intervencion Cutab \\ Department of Education, Tagum City Division, Philippines
}

\begin{abstract}
Jumping over the fence is a long-time problem not only in the school but also worldwide. For this reason, this study was conducted to determine the cause of the problem and provide implications. With the use of phenomenological research design, data gathered using Focus Group Discussion and In-Depth Interviews from the ten (10) purposively selected participants reveal that their reasons include boredom, bullying, recreation and preoccupation. Despite this, they also feared academic lag, and parental expectations. The findings of the research also reveal that the jumpers also faced several negative and positive consequences. In the light of these findings, implications and recommendations were presented in this manuscript.
\end{abstract}

Keywords: Jumping over the Fence, Senior High School, Cutting Class, Truancy

\section{INTRODUCTION}

Chool fence offers security and safety inside the school $\checkmark$ premises. It is what protects primarily the students from the strangers who could go in and out of the campus. Accordingly, without school fencing, the school grounds could be left open for kidnappers, sexual predators and feral animals plus the class-dodging activities that students are likely to commit (McBride, 2016).

However, with or without school fences, students learn to escape. In fact, in the study cited by. This could mean certain harm to the jumpers especially that their numbers are constantly increasing to ditch from their classes.

In England, a five-year old boy jumped over the fence to duck out his lessons. This happened despite the constant reminder of their head teacher about the dangers of jumping over the fences (Adams, 2015). Considering his age, pre-schools and elementary schools are not exempted from this appalling situation.

This scenario in fact is encountered by most of the schools in the Philippines. To decrease the number of jumpers, the Department of Education has ordered a tighter watch on the internet cafe's in school zones around the country after receiving a lot of reports of students cutting classes, in order to play online games or stay in social networking sites (Siytangco, 2019). Knowing that the school gate is close during class hours, students jump over the fence as an easy way to go outside the campus and escape from their classes (Adams, 2015).

Meanwhile, based on records, Jose Tuason Jr. Memorial National High School has a total of 179 recorded jumpers for the school 2016 - 2017 alone while 113 others were recorded recently from June to November 2019 (Genovia,
2019). It is clear that the number of jumpers has rapidly increased and warrants immediate attention.

With the information presented herein, the researcher finds it necessary to investigate on this jumping phenomenon at the school. If granted with permission, the research results and implications shall be utilized in crafting intervention programs in addressing the concerned issue.

This research endeavor seeks to answer the following questions:

1. What are the experiences of the student jumpers in Jose Tuason Jr. Memorial National High School?

2. What are the insights of the student jumpers in Jose Tuason Jr. Memorial National High School about jumping over the fence?

3. What are the possible interventions for this existing problem?

\section{MATERIALS AND METHODS}

This study is qualitative in nature. Specifically, this qualitative research used phenomenological design. Phenomenology will help in understanding the people's lived experiences. Creswell (2013) supports that phenomenology is a qualitative research method that is used when describing the experiences of human beings in a certain situation or phenomenon. Furthermore, through purposive snowball sampling technique, ten (10) participants were identified and interviewed. The participants were chosen using a set of criteria, called inclusion criteria, in order to gather only relevant data relative to the goals of the research. A researcher-made interview guide was utilized as the main data gathering tool. This interview guide was validated by three (3) experts to assure the validity of the questions to be asked. Ethical protocols were followed in the conduct of the study and necessary permissions were sought before the conduct of the study commenced.

The interview was recorded using audio recorder and transcribed by the researcher. The data were also translated into English language to allow understandability of the readers. Afterwards, the thick and descriptive data were analyzed by the researcher. In analyzing the data, the following series of steps were followed.

First, the researcher prepared and organized the gathered data into meaningful unit of analysis. In this step, it included transcribing the text and audio from the interview. Next step 
was reduction of experiences. This process involved reading the text numerous times. Then, the data were categorized and classified. The process of reducing data from chunks into cluster and codes created meaning of the gathered data.

Third, the researcher did the data interpretation and themes. In this process, it involved creating meaning for those cluster and with labels, this is called themes. Then, themes were interpreted to answer the questions.

And lastly, the researcher did the data representation. The researcher interpreted the data by reading and re-reading the transcripts, sorted, coded and inductively develop a thematic analysis.

A process of detecting, analyzing, and reporting patterns within data is known as thematic analysis (Braun \& Clarke, 2006). It is a widely used method of analysis in qualitative research. In this study, I searched for patterns and themes that were generated in the utterances or statements of the participants. Lastly, the final results were presented using matrices.

\section{RESULTS}

Table 1.1 Taxonomy of the Reasons of the Jumpers for Jumping Over the Fence

\begin{tabular}{|c|c|}
\hline Major Theme & Specific Concern \\
\hline \multirow{3}{*}{ Boredom } & Absence of teacher \\
\hline & Classroom discussion \\
\hline & Number of subjects \\
\hline \multirow{2}{*}{ Bullying } & Emotional pain \\
\hline & Backbiting \\
\hline \multirow{4}{*}{ Recreation } & Computer games \\
\hline & Sports \\
\hline & Vices \\
\hline & Rest \\
\hline \multirow{3}{*}{ Preoccupation } & Peer pressure \\
\hline & Freedom \\
\hline & Usual routine \\
\hline
\end{tabular}

Reasons of the Jumpers for Jumping Over the Fence

Students relate their jumping activities toa number of reasons. During the interview, the following are themes that were generated: (1) Boredom, (2) Bullying, (3) Recreations and (4) Preoccupation.

The jumpers mentioned that boredom is among the reasons they had for jumping. IDI 3 said that most of the time the teacher is not present because of meetings and conferences they attend to. As a result, they were left in the classroom doing some activities which can be done in less than an hour. IDI 3 even shared:

Sometimes, out teacher is not around because they have to attend meetings at the division office or at the city hall, so I decided to go out because I have nothing to do" IDI 3 $11 / 13 / 2018$
While the absence of the teacher matters a lot in the decision of the students whether to jump or not, the topic also is taken into account. FGD 4 expressed:

That moment when I cannot really understand the topic. Like that sir, the teacher discusses and I cannot understand. So, I would think it would be better if I go out than stay here when the same way I would not understand anything. FGD 4 $11 / 16 / 2018$

Aside from this, one of the uncontrollable circumstance that contribute to the number of jumpers in the school include the number of subjects. FGD 3 said:

Jumping comes to our mind sir because, this second semester, we only have four subjects" FGD 3 11/16/2018

On the other hand, while the instructor makes a concerted effort to encourage the pupils to remain in school, a few of their peers abuse them. IDI 2 shared that he wants to avoid emotional pain when bullied by his classmates. He said:

Sir, because my classmates always bully me and my looks, so I'd rather go out. IDI 2, 11/13/2018 FGD shared:

Meanwhile, backbiting also worsens the situation.

In the classroom ma'am, most of them criticize my...my looks. Then they make fun of you and bully you. Just like the girls, they backbite me even if I did not do anything wrong. FGD 6 $11 / 16 / 2018$

Moreover, the participants also included recreational activities as those that also push them to leave the school and jump. There are those peers who negatively influenced them. FGD 6 expressed:

That moment that you want to study well even without money but your close friend would entice you to jump together.

FGD 6 11/16/2018 FGD 4 added:

For me sir, I usually stay by a store. Then I buy cigarette and smoke, and I go with the two of them sir. We always go together. FGD 4 11/16/2018

Aside from those who are socially influenced, there also those who jump because they just want to rest. FGD 3 shared: I could take a long, long rest. FGD 3 11/16/2018

On the other hand, the students also revealed that one of their reasons for jumping is preoccupation. FGD 6 shared:

That moment that you want to study well even without money but your close friend would entice you to jump together. FGD $611 / 16 / 2018$

Further, the participants also shared that jumping is a liberating activity. FGD 4 shared:

The best thing about jumping sir is that you can do anything that you want. No one can stop you and you are free to do anything. FGD 4 11/16/2018 
Meanwhile, aside from these, the participants also shared that they jump because it is just the activity that they are used to do since then. FGD 3 shared:

It is really the fault of the students, sir. Sometimes, they cannot understand the discussion because they always think of jumping like they are used to do it. FGD 3 11/16/2018

Table 1.2 Taxonomy of the Fears of the Jumpers when Jumping Over the Fence

\begin{tabular}{|c|c|}
\hline Major Theme & Specific Concern \\
\hline \multirow{2}{*}{ Academic lag } & Failure \\
\cline { 2 - 2 } & No Learning \\
\hline \multirow{2}{*}{ Parental Expectation } & Trust \\
\cline { 2 - 2 } & Financial aspect \\
\hline
\end{tabular}

Fears of the Jumpers when Jumping Over the Fence

While the participants shared their reasons for jumping, they also shared their fears for doing such. This includes (1) academic lag, and (2) parental expectations. Among the academic related concerns, the participants were afraid that they are going to fail in many ways. IDI 2 shared:

I am always afraid that I will fail, not attending my classes.

IDI 2 11/13/2018 FGD 5 added:

For me sir, it is really wrong to jump. It makes me feel anxious that I did not learn anything and then my grades will become low. FGD 5 11/16/2018

Furthermore, aside from their fear in their academic standing in the school, the participants are also afraid how their family might react with this activity. FGD 4 shared:

For me sir, if I always jump, my parent would not be proud of me anymore. They will lose their trust in us and they will think that if they send me to school, I would still do it. FGD 4 11/16/2018 FGD 3 also revealed:

Of course sir, I would be afraid that my grades will become low and my parents would feel that the money they spent to us is useless... FGD 3 11/16/2018

Table 2 Taxonomy of the Insights of the Jumpers for Jumping Over the Fence

\begin{tabular}{|c|c|}
\hline Major Theme & Specific Concern \\
\hline \multirow{4}{*}{ Negative Effects } & Grades \\
\cline { 2 - 2 } & Attendance \\
\cline { 2 - 2 } & Health \\
\cline { 2 - 2 } & Learning \\
\cline { 2 - 2 } & Vices \\
\cline { 2 - 2 } & School requirement \\
\hline \multirow{2}{*}{ Positive Effects } & Household chores \\
\cline { 2 - 2 } & Early rest \\
\hline
\end{tabular}

Insights of the Jumpers for Jumping Over the Fence

In addition to the fears shared, the participants are also aware of the (1) positive and (2) negative consequences of their actions. Among the negative insights they shared, everyone agreed about the academic standing. IDI 3 shared two points:

I would receive low scores during quizzes and consequently grades. IDI 3 11/13/2018 ...second sir, we will not learn anything... FGD 3 11/16/2018 IDI also agreed:

Since I jump, the negative effects are on my attendance and quizzes. IDI 1 11/09/2018 FGD 7 added:

For me sir, when you always jump, you will be blink as to the tasks in the room and projects. FGD 7 11/16/2018

Aside from the academic lag, the participants are also aware its repercussions towards their health. IDI 1 shared:

...it was the reason why I got an ulcer. IDI 1 11/09/2018 He furthered:

When I was grade 10 sir at the back of the HE, someone offered me a solvent sir. IDI 1 11/09/2018

However, while they are generally negatively judged, the participants shared their predicament on how their absences due to jumping help their family. FGD 6 shared:

For me sir, the good thing about jumping is that my mother can send me errands like fetch my younger brother from the school, buy something from the store and help wash clothes. FGD 6 11/16/2018

Meanwhile, resting was also one of the good things they get from it. FGD 3 shared:

I could rest very early sir. FGD 3 11/16/2018

\section{DISCUSSION}

Presented in this section are the discussion of the themes together with the interpolation of relevant literature.

Reasons of the Jumpers for Jumping Boredom

During the interviews, the participants agreed that boredom was one of their reasons for jumping. Morin (2018) wrote that most of the time students get bored because they are not challenged enough in the classroom. With this, Gosline (2007) posit that these bored students have the tendency to show erratic behaviors which include jumping. With this, Hoehn (2020) suggested ways to combat boredom in the classroom which included trying new activities, trying multiple activities at the same time and trying new routine.

Bullying

Unicef (2019) reported that half of Filipino children aged 13-17 were victims of bullying in many forms. With this, Gordon (2021), such victims would have the tendency to keep silent, repress their emotions and get erratic decisions in life such as cutting classes. Patchin (2017) termed this event as 
jumping or truancy. With this, Spocchia (2021) specifically wrote to take note of bullying signs in order to mitigate from this dangerous behaviors of the victims

\section{Recreation}

During the interview, most of the students agree that they have instructional difficulty. With this, they jump. However, they also shared that they go out with their friends, jump over the fence in order to have fun and play video games in internet cafes. Elter (2018) listed out reasons for students' cutting classes and indeed, recreation or having fun was one of them. She wrote that peer acceptance is important for the students; hence, they jump to strengthen their bond. Davis (2021) similarly said that when cutting classes, their friends usually cover for them. Then, they just meet outside and play sports of online games. Peer pressure are flagrant during teenage period (Lyness, 2015).With this, Briggs (2015) gave suggestions on how not to be a boring teacher and avoid such jumping activities. One of them was to show that you truly care for the students.

\section{Preoccupation}

When interviewed, the participants shared that when they jump on a certain day, they felt like they want to do it over and over again. They agreed that this was the feeling that always linger on their minds during the same period of the day everyday. In the study of Taylor (2012), he wrote that the preoccupied minds of the students pose a great danger to their academic efforts. He mentioned that they have the tendency to lose focus and just do the things that they felt like doing. With this, Lee (2016) suggested that homeschooling would be better than this happening everyday. Fernando (2019) pointed out that preoccupation in the minds of the students was caused by lack of interest in school. This feeling of laziness on the part of the students causes their lack of motivation and encourages them to jump over the fence to cut classes. Davis (2021) advised that such students must be checked for possible mental health challenges which John Hopkins University (2021) wrote could help balance the students school and personal life.

\section{Fears of the Jumpers for Jumping Academic Lag}

While students feels they have emotional satisfaction when jumping because they feel that they are free, they also have some feeling of guilt and fear. One of them is the fear academic lag or fear to fail their subjects. Fernando (2019) wrote that students still have this fear of not passing their subjects because of cutting classes. He added that they are aware of their class rules before jumping. Musgrove 92016) also pointed out that some students who jump are afraid that their family could get summoned because of their erratic behavior in the school.

\section{Parental Expectation}

Generally, the participants agree that they are afraid of their parents finding out their misbehaviors. In fact, Bledsoe and Baskin (2015) that their fear is mostly due to cultural factors or parental pressure to do good or better than their performing relatives or friends. They added that too much anxiety leads to erratic behaviors like this. This is supported by Fernando (2019) who also advocated parental support as important factors for students to do better in school.

\section{Insights of the Jumpers for Jumping Negative Effects of Jumping}

Taylor (2012) has earlier mentioned how cutting classes or jumping over the fence could endanger a students academic life. During the interview with the participants, they generally agree that school-related activities could be harmed because of cutting classes. This was backed by Taylor who studied the negative effects of jumping towards a student' grades. Aside from this, Mondares, et. al. (2019) stressed how academic performance is affected by jumping. With this, Fernando (2019) advocated a mental health check for students who have this kind of recurring misbehaviors.

\section{Positive Effects of Jumping}

According to the participants, there could also be positive effects for cutting class. They mentioned that it gives them more time to rest and help their family in the household chores. Diamantakos (2017) suggested that in between classes, there should be more time to rest Accordingly, it gives the students with better strength and power to do activities and tasks. Similarly, Wood (2021) also advised that there should also be shorter school days and class time. Moreover, Scundamore (2016) wrote that skipping classes made him a better entrepreneur because it gave him a chance to draw his own path and to decide when and when not to be in the school.

\section{CONCLUSION}

Based on the findings of this research, the following implications for practice and recommendations are suggested in order to aid the educational planners, policy makers and other education actors in enforcing protection for the students and teachers. These suggestions are specific for Jose Tuason Jr. Memorial National High School but may apply to other schools experiencing the same problems.

- The school head,

> in partnership with the Local Government of Tagum, needs to hire additional security personnel for the school in order to man the different 'jumping areas' of the students;

$>$ with the Parents Teachers Association and the School Governing Council, needs to fund improvement of the old and low lying school fencing of the school premises;

$>$ in cooperation with the Child Friendly School System (CFSS), Guidance Counsellors and Advocates, and the Chief Disciplinarian, needs to strengthen implementation of the school rules and 
regulations especially with the punishments and rewards provisions;

- The teachers,

in partnership with the school head, are encouraged to adopt reward system for student attendance which is hoped at decreasing number of student jumpers;

$>\quad$ in partnership with the School Guidance Counsellor, are encouraged to remind the students about the repercussions of bullying citing the law governing it.

It is the ultimate wish of the author to see how the school, the Division of Tagum City and the Department of Education as a whole will consider these recommendations in order to improve students' learning experiences and outcomes as well as primarily promoting their safety, security and protection inside the school. Further, it is hoped that these students will restore their trust, and confidence to the school and in other education sectors; hence, will eventually enable them to become better citizens of the country.

\section{REFERENCES}

[1] Adams, m. (2015, January 15). Five-year-old leaves school unnoticed by jumping fence and walking half a mile home Education.

[2] Bledsoe, S., \& Baskin, J. (2015, April 27). Strategies for Addressing Student Fear in the Classroom. Teachaing and Learning.

[3] Briggs, S. (2015, October 10). Informed. Retrieved from https://www.opencolleges.edu.au/: https://www.opencolleges.edu.au/informed/features/refuse-to-bea-boring-teacher/'

[4] Davis, B. (2021, May 3). MV Organizing. Retrieved from https://www.mvorganizing.org/: https://www.mvorganizing.org/what-are-the-causes-of-skippingclasses/

[5] Davis, R. (2021, September 28). Best Colleges. Retrieved from https://www.bestcolleges.com/:

https://www.bestcolleges.com/resources/top-5-mental-healthproblems-facing-college-students/

[6] Diamantakos, C. (2017, July 25). Clear Cut Fitness. Retrieved from https://www.clearcut-fitness.com/: https://www.clearcutfitness.com/blog/2017/7/25/how-long-should-you-rest-in-betweensets

[7] Etler, C. (2018, November 8). What to Do if Your Teen Is Cutting Class. Parenting.

[8] Fernando, S. (2019, December 5). Factors that affects class cutting. Parenting.

[9] Genovia, S. (2019). Number of Jumpers in Jose Tuason Jr. Memorial National High School. Tagum.

[10] Gordon, S. (2021, February 27). Very Well Family. Retrieved from https://www.verywellfamily.com/reasons-why-victims-of bullying-do-not-tell-460784

[11] Gosline, A. (2007, February 26). Scientific American. Retrieved from https://www.scientificamerican.com/: https://www.scientificamerican.com/article/the-science-ofboredom/

[12] Hoehn, T. (2020, September 24). Mayo Clinic Health System. Retrieved from https://www.mayoclinichealthsystem.org/: https://www.mayoclinichealthsystem.org/hometownhealth/speaking-of-health/prevent-boredom-and-injury-duringphysical-activity

[13] John Hopkins University. (2021). John Hopkins University. Retrieved from https://jhsap.org/: https://jhsap.org/self_help_resources/school-life_balance/

[14] Lee, L. (2016, July 16). National Home Education Research Institute. Retrieved from https://www.nheri.org/: https://www.nheri.org/home-school-researcher-cutting-classexperiences-of-gifted-adolescents-who-switched-tohomeschooling/

[15] Lyness, D. (2015, July). Nemours Kids' Health. Retrieved from https://kidshealth.org/: $\quad$ https://kidshealth.org/en/kids/peerpressure.html

[16] McBride, M. (2016, May 31). Protective. Retrieved from https://profence.com.au/.

[17] Mondares, L., Baring, T., Marikit, M., \& Dayday, A. (2019). The Cause and Effect of Cutting Classes Towards The Academic Performance of Junior High Students of Maya National.

[18] Morin, A. (2020, July 18). Very Well Family. Retrieved from https://www.verywellfamily.com/: https://www.verywellfamily.com/reasons-kids-are-bored-atschool-620804

[19] Musgrove, L. (2016, May 24). Inside Higher Ed. Retrieved from https://www.insidehighered.com/: https://www.insidehighered.com/advice/2016/05/24/importanceteaching-students-not-fear-essay

[20] Patchin, J. (2017, January 3). Cyberbullying Research Center. Retrieved from https://cyberbullying.org/: https://cyberbullying.org/millions-students-skip-school-yearbullying

[21] Richmond, E. (2012, August 30). Who's Really Skipping School? Education.

[22] Scudamore, B. (2016, April 27). Forbes. Retrieved from https://www.forbes.com/: https://www.forbes.com/sites/brianscudamore/2016/04/27/4-wayscutting-class-made-me-a-better-entrepreneur/?sh=6db52f 236779

[23] Siytangco, A. (2019, June 24). Reports of students cutting classes just to go to internet shops alarm QC councilors. Education.

[24] Spocchia, G. (2021, May 11). Boy, 11, jumps from bus 'to avoid bullying': 'He could have lost his life'. Americas.

[25] Taylor, L. (2012). Cutting Class Harms Grades. Decision Sciences Journal of Innovative Education.

[26] Unicef. (2019). Online bullying remains prevalent in the Philippines, other countries. Unicef.

[27] Wood, B. (2021). Classroom. Retrieved from https://classroom.synonym.com/:

https://classroom.synonym.com/pros-cons-lengthening-schoolday-8209249.html 